\title{
Perancangan Sistem Informasi Akuntansi Pada IQ Salon
}

\author{
Kartika Imam Santoso $^{a^{*}}$, Cisilia Sundari ${ }^{\mathrm{b}}$, Putri Kusumasari ${ }^{\mathrm{c}}$ \\ a,b,c Prodi Sistem Informasi, STMIK BINA PATRIA, Magelang
}

Naskah Diterima : 14 Oktober 2014; Diterima Publikasi : 12 Nopember 2014

\begin{abstract}
Recording of transactions and financial statements of the manual on IQ Salon raises the risk of error in the financial records are not fast and precise, and cause difficulties with the increasing transaction will occur in the future. The purpose of this research is to design accounting information systems (AIS) to prepare financial statements to the income statement and provide convenience in recording daily transactions and the financial statements in order to avoid mistakes. The design used in this study is a Waterfall and programming used is PHP and MySQL as the database. The design uses modeling context diagram, Data Flow Diagrams (DFD), Entity Relationship Diagram (ERD). Accounting information system on IQ Salon built using the programming language PHP and MySQL as the database generates Journal report, Balance Sheet and Income Ledger. The report simplify IQ Salon owners to control and make decisions. It is also easier for employees to serve customers in the event of payment of the services that have been awarded
\end{abstract}

Keywords : DFD; IQ Salon; MySQL; PHP; IAS; Waterfall

\begin{abstract}
Abstrak
Pencatatan transaksi dan laporan keuangan yang masih manual pada IQ Salon menimbulkan resiko kesalahan dalam pencatatan keuangan tidak cepat dan tepat, serta menimbulkan kesulitan dengan semakin meningkatnya transaksi yang akan terjadi kedepannya. Tujuan penelitian ini adalah untuk merancang sistem informasi akuntansi (SIA) yang dapat menyusun laporan keuangan sampai laporan rugi laba dan memberi kemudahan dalam mencatat transaksi harian dan laporan keuangan agar tidak terjadi kesalahan. Perancangan yang digunakan dalam penelitian ini adalah Waterfall dan pemrograman yang digunakan adalah PHP \& MySql sebagai databasenya. Perancangan menggunakan permodelan Diagram Kontek, Data Flow Diagram (DFD), Entity Relationship Diagram (ERD). Sistem informasi akuntansi pada IQ Salon yang dibangun dengan menggunakan bahasa pemrograman PHP dan MySQL sebagai databasenya menghasilkan laporan Jurnal, Buku Besar, Neraca, dan Rugi Laba. Laporan tersebut mempermudah pemilik IQ Salon untuk mengontrol dan mengambil keputusan. Selain itu juga mempermudah karyawan untuk melayani pelanggan dalam hal pembayaran dari layanan yang telah diberikan.
\end{abstract}

Keywords : DFD; IQ Salon; MySQL; PHP; SIA Waterfall

\section{Pendahuluan}

IQ Salon adalah usaha kecantikan yang melayani berbagi macam perawatan seperti potong rambut, lulur dan masih banyak lagi. Usaha ini berjalan hampir satu tahun. Sebelunmya IQ Salon hanya dikelola semua oleh pemilik dan hanya mempunyai 1 karyawan, semakin banyak minat pelanggan yang melakukan perawatan saat ini IQ Salon mempunyai 4 karyawan. Semakin banyak pelanggan pemilik salon sering lupa mencatat keuangan pada salon sehingga tidak akurat dalam proses keuangan salon.

Kelemahan pada IQ Salon yaitu dalam mencatat laporan keuangan yang masih manual, sehingga proses tersebut akan menimbulkan resiko kesalahan dalam pencatatan keuangan tidak cepat dan tepat, serta menimbulkan kesulitan dengan semakin meningkatnya transaksi yang akan terjadi kedepannya. Untuk mengatasi berbagai kesalahan

*) Penulis korespondensi: kartikaimams@gmail.com dalam membuat laporan keuangan, maka akan dibangun sistem informasi akuntansi untuk pencatatan laporan keuangan sehingga lebih cepat,tepat dan akurat.

Dilihat dari permasalahan diatas, maka akan dibuatkan Sistem Informasi Akuntansi Pada IQ Salon agar dapat memudahkan dalam pembuatan laporanlaporan sampai ke laporan laba rugi sehingga dapat meningkatkan efektifitas dan efisiensi dalam hal waktu serta biaya operasional.

\section{Kerangka Teori}

\subsection{Sistem}

Definisi sistem menurut Mulyadi (2001) adalah sebagai berikut: "Suatu sistem pada dasarnya adalah sekelompok unsur yang erat berhubungan satu dengan lainnya, yang berfungsi bersama-sama untuk mencapai tujuan tertentu." 
Menurut Widjayanto (2001) "Sistem adalah sesuatu yang memiliki bagianbagian yang saling berinteraksi untuk mencapai tujuan tertentu melalui tiga tahapan yaitu: input, proses dan output".

Menurut Hall (2001) "sebuah sistem adalah sekelompok dua atau lebih komponen-komponen yang saling berkaitan (inter-related) atau subsistemsubsistem yang bersatu untuk mencapai tujuan yang sama (common purpose)."

\subsection{Sistem Akuntansi}

Sistem Akuntansi Warren, Reeve, dan Fess (2005) mengemukakan bahwa: "Sistem akuntansi adalah metode dan prosedur untuk mengumpulkan, mengklasifikasikan, mengikhtisarkan, dan melaporkan informasi operasi dan keuangan sebuah perusahaan."

Menurut Mulyadi (2001) "sistem akuntansi adalah organisasi formulir, catatan, dan pelaporan yang dikoordinasikan sedemikian rupa untuk menyediakan informasi keuangan yang dibutuhkan oleh manajemen guna memudahkan pengelolaan data perusahaan".

\subsection{Sistem Informasi Akuntansi}

Menurut Bodnar dan Hopwood (2004) : "Sistem informasi akuntansi (SIA) adalah kumpulan sumber daya, seperti manusia dan peralatan yang diatur untuk mengubah data keuangan dan data lainnya menjadi informasi".

Romney dan Steinbart (2004) menyatakan bahwa "Sistem informasi akuntansi (SIA) adalah sumber daya manusia dan modal dalam organisasi yang bertanggungjawab untuk (1) persiapan informasi keuangan dan (2) informasi yang diperoleh dari mengumpulkan dan memproses berbagai transaksi perusahaan".

Menurut Jogiyanto (2007) "Sistem Informasi Akuntansi adalah kumpulan kegiatan-kegiatan dari organisasi yang bertanggung-jawab untuk menyediakan informasi keuangan dan informasi yang didapatkan dari transaksi data untuk tujuan pelaporan internal kepada manajer untuk digunakan dalam pengendalian dan perencanaan sekarang dan operasi masa depan serta pelaporan eksternal kepada pemegang saham, pemerintah, dan pihak-pihak luar lainnya."

Menurut Gondodiyoto (2007), penerapan komputerisasi pada SIA, menyebabkan enam perubahan di dalam sistem. Perubahan tersebut adalah sebagai berikut:

1. Perubahan terhadap struktur organisasi Pada perusahaan yang besar, penerapan komputerisasi akan menimbulkan suatu departemen baru, yaitu departemen komputer atau departemen pengolahan data elektronik atau departemen sistem informasi.

2. Perubahan terhadap simpanan data Pada sistem manual data dicatat di jurnal dan buku besar.
Pada sistem komputerisasi, data disimpan di file dalam bentuk yang hanya dapat dibaca oleh mesin.

3. Perubahan pemrosesan volume data besar yang rutin Pemrosesan secara terkomputerisasi dapat beroperasi dengan lebih cepat, tepat, konsisten, dan dapat dilakukan secara terus menerus dalam waktu yang relatif tidak terbatas.

4. Perubahan terhadap ketersediaan informasi Sistem secara terkomputerisasi dapat menyediakan informasi pada saat yang dibutuhkan.

5. Perubahan dalam pengendalian internal Dengan diterapkannya sistem secara terkomputerisasi, maka pengendalian internal juga akan mengalami perubahan, terutama pada pengendalian akuntansi.

6. Perubahan penelusuran akuntansi Pada sistem secara terkomputerisasi, penelusuran akuntan (audit trail) menembus sistem komputer. Pemeriksaan ini disebut dengan audit through computer. Audit through computer adalah pemeriksaan langsung terhadap programprogram dan file-file komputer pada sistem informasi berbasis teknologi informasi (TI).

Pada SIA yang terkomputerisasi terdapat input, proses, dan output dalam mengolah data, dibutuhkannya pengendalian internal dalam pengolahan data tersebut agar menghasilkan data yang baik bagi perusahaan, Suwarno (2004) menjelaskan sebagai berikut:

1. Pengendalian Input

Pengendalian input bertujuan untuk menjamin bahwa data yang diterima untuk diproses telah diotorisasi, lengkap, bebas dari kesalahan, diidentifikasi menjadi data yang dapat dibaca oleh mesin (komputer).

2. Pengendalian Proses

Pengendalian proses bertujuan untuk mencegah kesalahan yang terjadi selama proses data dimasukkan ke komputer.

3. Pengendalian Output

Pengendalian output bertujuan untuk menjamin ketelitian dalam memproses hasil dan menjamin bahwa pihak yang berhak saja yang menerima output.

\subsection{Proses dan Siklus Akuntansi}

Menurut Tjahjono dan Sulastiningsih (2003), "Siklus Akuntansi adalah langkah-langkah dalam akuntansi formal dimulai dari analisis terhadap transaksi bisnis, mencatat dalam buku jurnal dan diakhiri dengan penyusunan daftar saldo setelah penutupan." Sistem informasi akuntansi tidak lepas dari siklus akuntansi yang meliputi urutan siklus sebagai berikut:

1. Analisis transaksi bisnis, seperti pengumpulan bukti-bukti transaksi yang terjadi

2. Menjurnal transaksi-transaksi tersebut 
3. Mem-posting jurnal tersebut ke buku besar (general ledger)

4. Menyiapkan neraca saldo

5. Menjurnal dan mem-posting penyesuaian (jurnal penyesuaian)

6. Menyiapkan neraca penyesuaian

7. Menyiapkan laporan keuangan, berupa laporan laba rugi (income statement), laporan perubahan modal ( statement of equity) dan neraca saldo (balance sheet)

8. Menjurnal dan mem-posting penutup (jurnal penutup)

9. Menyiapkan neraca penutup.

\section{Metodologi}

\subsection{Tahap pengumpulan data}

Pada tahap ini hal-hal yang dilakukan dalam penelitian adalah:

1. Studi Literatur yaitu dengan mencari literatur dari buku dan jurnal yang sesuai dengan penelitian

2. Observasi yaitu dengan melihat kegiatan-kegiatan transaksional pada obyek penelitian yaitu di IQ Salon

3. Interview yaitu dengan melakukan tanya jawab dengan pemilik dan karyawan pada IQ Salon

\subsection{Tahap pembuatan perangkat lunak}

Model proses yang digunakan pada penelitian ini adalah dengan metode Waterfall, yang tahapannya adalah sebagai berikut :

1. Analisis, analisis yang digunakan adalah dengan analisa PIECES, untuk mencari kelemahan dan masalah yang ada pada sistem yang sedang berjalan.

Berikut adalah hasil analisis terhadap sistem lama di IQ Salon :

a. Analisis Kinerja Sistem (Perfomance)

Kinerja merupakan bagian pendukung kelancaran proses kerja dalam suatu perusahaan atau intansi. Kinerja yang dimaksud adalah kerja sistem. Kinerja dapat diukur dari throughput dan response. Throughput adalah jumlah dari pekerjaan yang dapat dilakukan oleh sistem tertentu. Response time adalah jumlah rata-rata waktu yang tertuang diantara dua pekerjaan ditambah dengan waktu respone untuk menanti pekerjaan tersebut. Sistem keuangan yang berjalan di IQ Salon dilakukan secara manual, belum ada dukungan dari sistem yang terkomputerisasi

b. Analisis Informasi (Information)

Informasi yang dimaksud disini ialah sebuah informasi tentang keuangan IQ Salon. Dengan sistem yang ada, informasi keuangan yang di sajikan kurang efektif. Sehingga pemilik kurang maksimal dalam menerima informasi tentang keuangan yang ada. c. Analisis Ekonomi (Economy)

Secara ekonomi sistem lama masih sering terjadi kesalahan dalam proses transaksi dan rekapitulasi keuangan.

d. Analisis Pengendalian (Control)

Control lebih ditujukan untuk pengawasan kondisi keuangan di IQ Salon, bagaimana laju keuangan yang terjadi.

e. Analisis Efisiensi (Efficiency)

Efisien berhubungan dengan waktu bagaimana sistem keuangan berjalan dalam melakukan proses keuangan. Sistem keuangan yang ada masih secara manual. Hal itu menyebabkan proses menjadi tidak akurat dan membutuhkan waktu yang lama.

f. Analisis Pelayanan (Service)

Pelayanan yaitu sebuah penyampaian laporan kepada pemilik seputar keuangan yang ada di IQ Salon. Sistem yang ada belum bisa menyajikan informasi yang lengkap dan memuaskan.

Berdasarkan Analisa PIECES diatas maka bisa diambil kesimpulan bahwa sistem yang sedang berjalan mempunyai kelemahan antara lain :

a. Sistem keuangan yang berjalan di IQ Salon dilakukan secara manual, belum ada dukungan dari sistem yang terkomputerisasi.

b. Dengan sistem yang ada, informasi keuangan yang di sajikan kurang efektif. Sehingga pemilik kurang maksimal dalam menerima informasi tentang keuangan yang ada.

c. sistem lama masih sering terjadi kesalahan dalam proses transaksi dan rekapitulasi keuangan .

d. Bagian keuangan tidak bisa menyajikan laporan keuangan yang berkualitas karena sumber data kurang lengkap.

e. Sistem keuangan yang ada masih secara manual. Hal itu menyebabkan proses menjadi tidak akurat dan membutuhkan waktu yang lama.

f. Sistem yang ada belum bisa menyajikan informasi yang lengkap dan memuaskan.

Berdasarkan analisa tersebut di atas maka dilakukan tahapan selanjutnya yaitu merancang sistem yang baru.

2. Perancangan, yaitu melakukan perancangan dengan membuat

a. Diagram Kontek pada gambar 1.

b. DFD pada gambar 2 .

c. ERD pada gambar 3.

d. Database dan Tabel pada gambar 4.

3. Implementasi, yaitu membuat program dengan PHP dan MySql sebagai databasenya.

4. Pengujian, yaitu melakukan pengujian dari Aplikasi yang telah dibuat. 


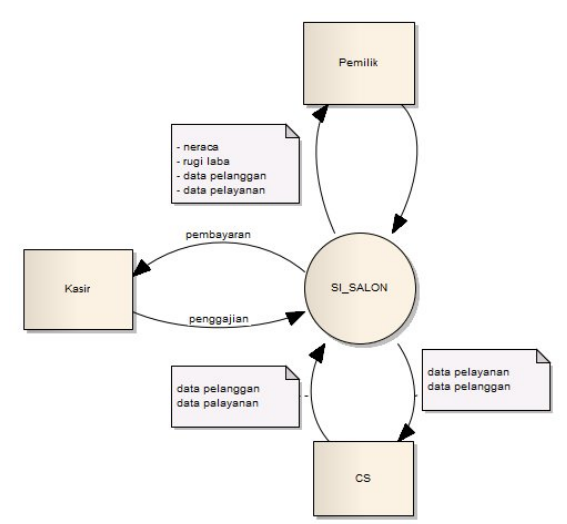

Gambar 1. Diagram kontek

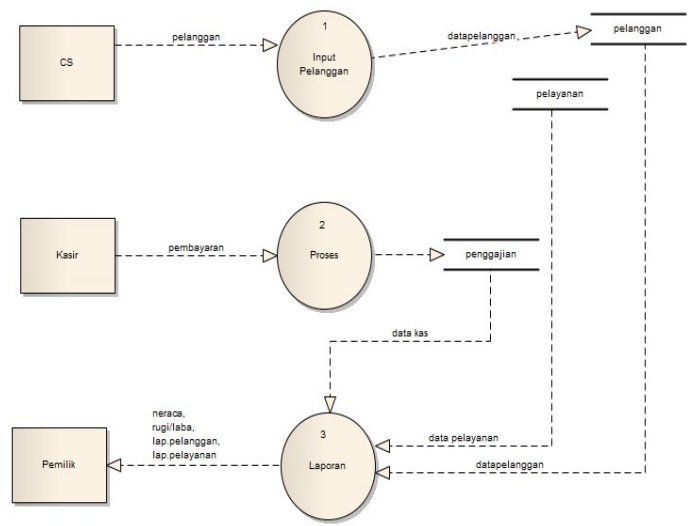

Gambar 2. DFD

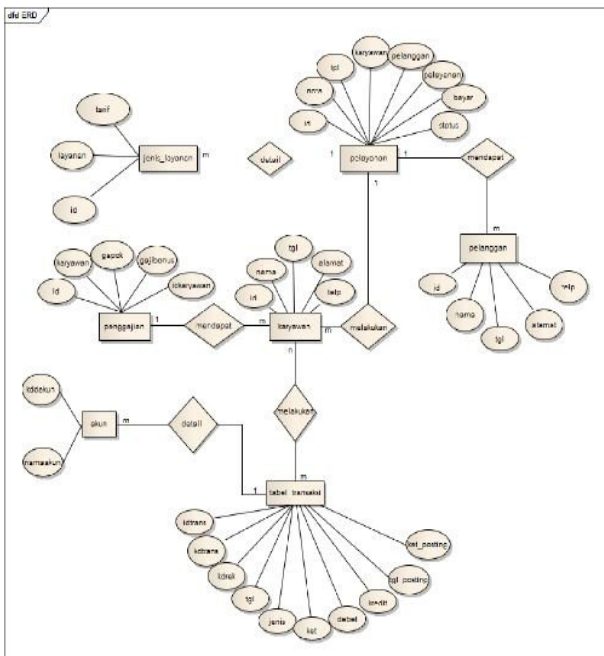

Gambar 3. ERD

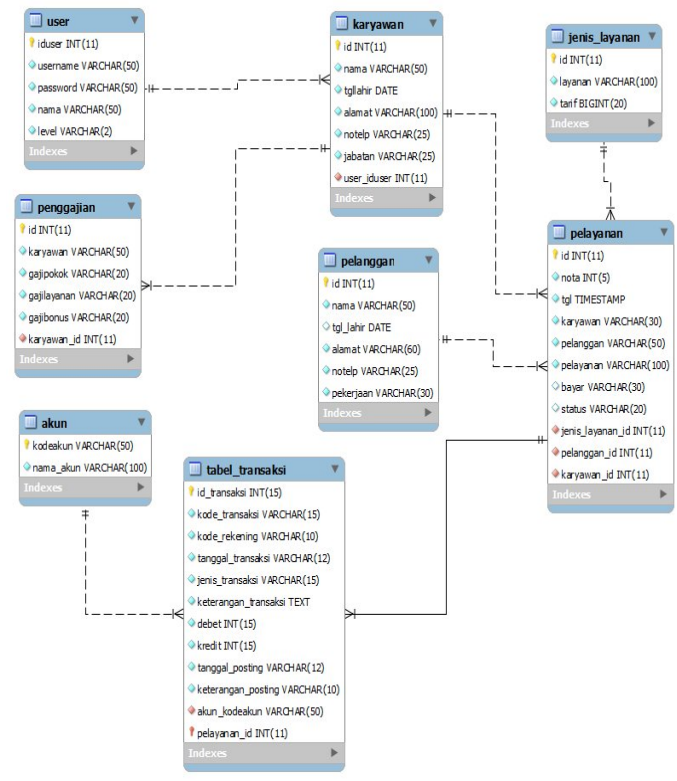

Gambar 4. Tabel dan relasinya

\section{Hasil dan Pembahasan}

Hasil penelitian ini berupa sistem informasi akuntansi dimana formulir-formulir, catatan-catatan, prosedur-prosedur dan alat-alat yang digunakan untuk mengolah data mengenai usaha (jasa IQ Salon) merupakan suatu kesatuan ekonomis yang bertujuan untuk menghasilkan informasi dalam bentuk laporanlaporan antara lain laporan data Pelanggan, Nota pembayaran, jurnal, neraca dan buku besar yang diperlukan oleh manajemen untuk pengawasan dan pengambilan keputusan dalam menjalankan operasinya.

Aplikasi sistem informasi akuntansi IQ Salon terdiri dari halaman login seperti pada gambar 5 digunakan untuk masuk ke dalam sistem. Level User yang digunakan untuk login adalah Administrator untuk pemilik salon, dan Operator untuk Kasir.

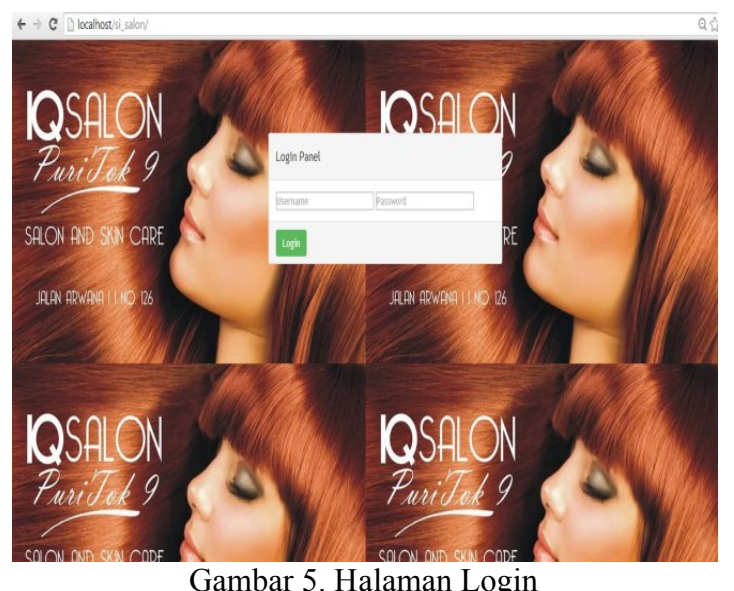


Pada sisi login menggunakan username administrator maka akan muncul halaman administrator seperti pada gambar 6 berikut ini.

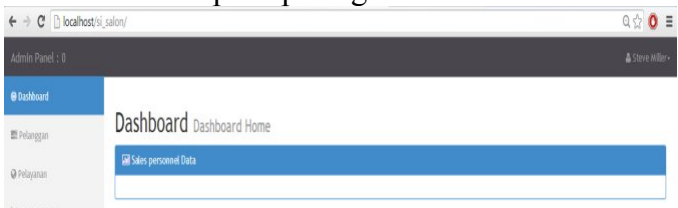

Gambar 6. Halaman administrator

Pada halaman Administrator ini fasilitas yang diberikan adalah untuk mengelola data Pelanggan, layanan dan tarif, pembayaran layanan oleh pelanggan, data karyawan dan penggajian, memasukkan perkiraan mencetak laporan neraca, buku besar, jurnal, rugi laba.

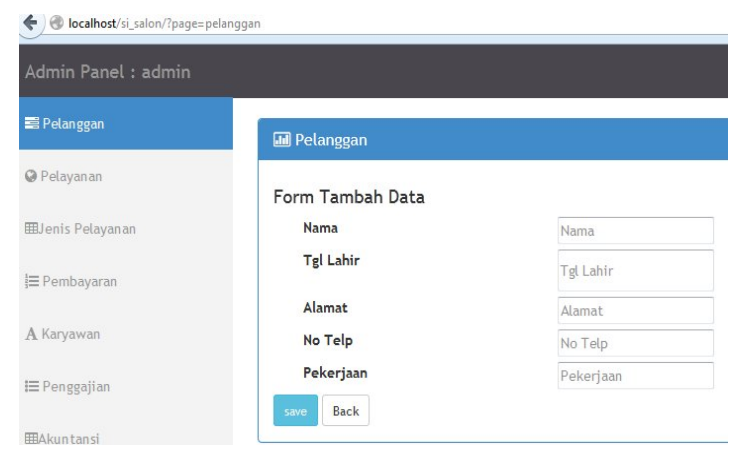

Gambar 7. Halaman data pelanggan

Halaman ini digunakan oleh administrator dan Kasir untuk memasukkan data pelanggan.

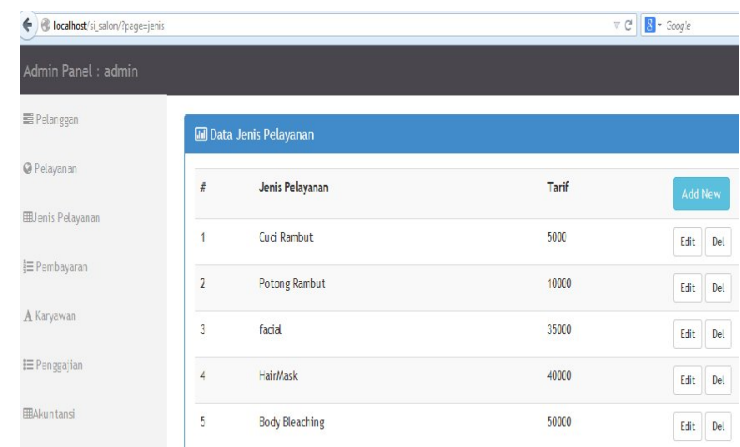

Gambar 8. Layanan dan tarif

Halaman ini digunakan oleh administrator dan Kasir untuk memasukkan data layanan dan tarifnya.

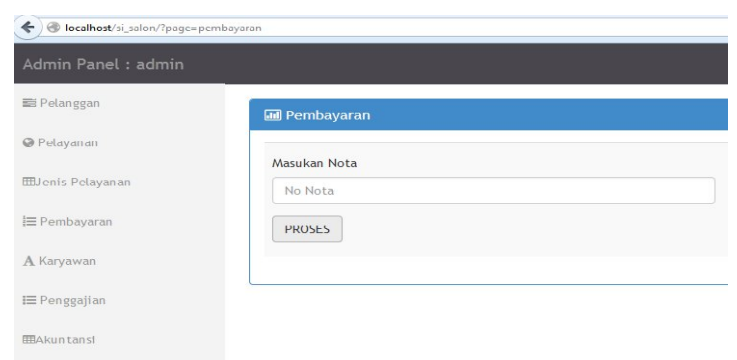

Gambar 9. Halaman pembayaran

Halaman ini digunakan oleh administrator dan Kasir untuk memasukkan pembayaran oleh pelanggan sesuai dengan layanan yang dilakukan.

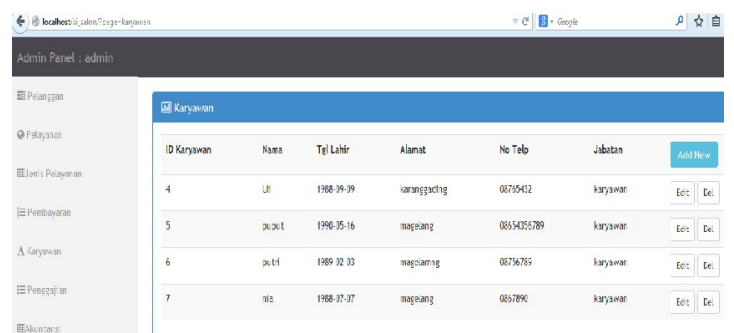

Gambar 10. Halaman data karyawan

Halaman ini digunakan oleh administrator untuk memasukkan data karyawan salon.

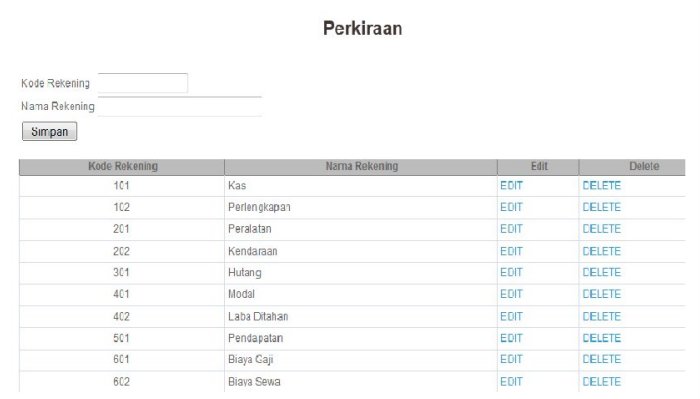

Gambar 11. Halaman data perkiraan

Halaman ini digunakan oleh administrator untuk memasukkan data perkiraan atau no rekening atau no akuntansi.

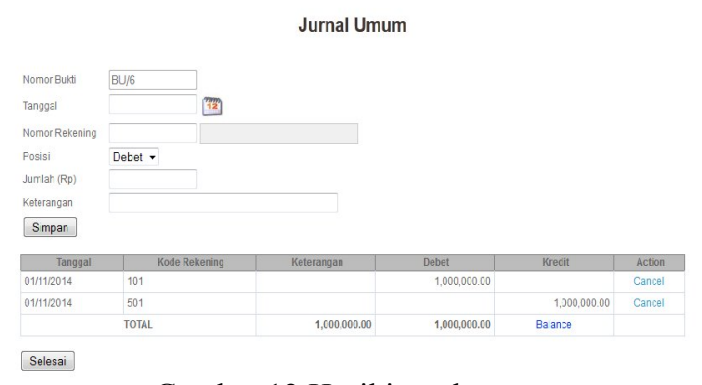

Gambar 12 Hasil jurnal umum

Halaman ini digunakan oleh administrator untuk melihat atau mencetak Jurnal Umum. 

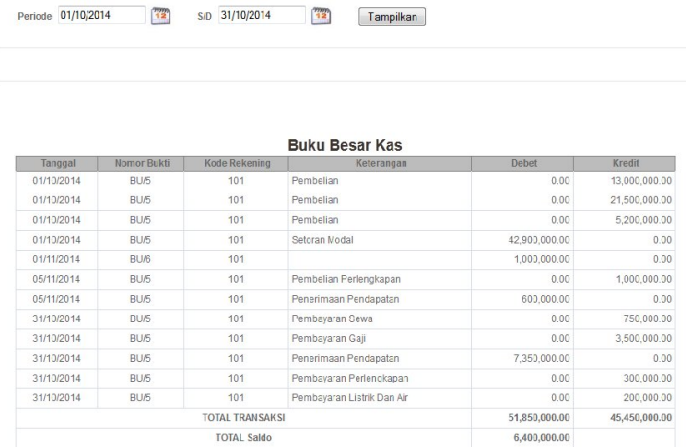

Gambar 13. Hasil buku besar

Halaman ini digunakan oleh administrator untuk melihat atau mencetak Buku Besar.

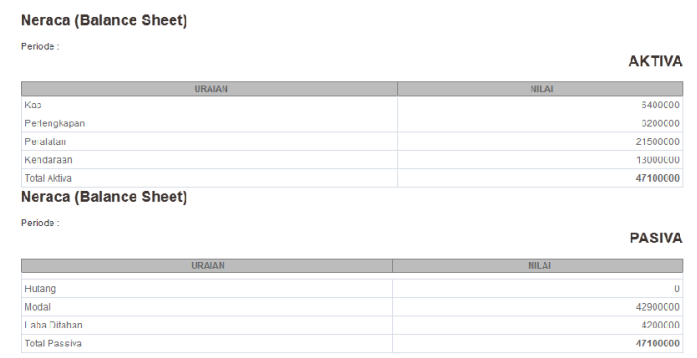

Gambar 14. Hasil neraca

Halaman ini digunakan oleh administrator untuk melihat atau mencetak Neraca.

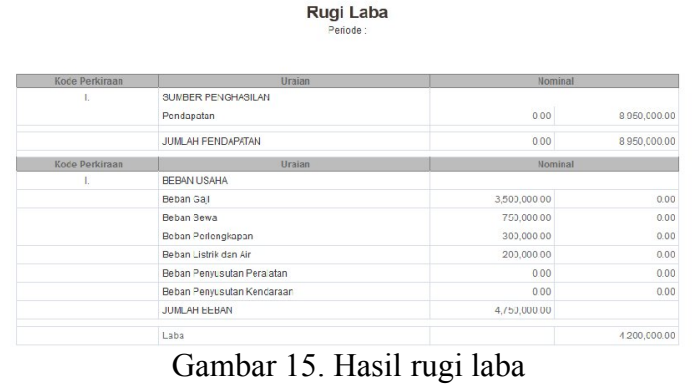

Halaman ini digunakan oleh administrator untuk melihat atau mencetak Laporan Rugi Laba.

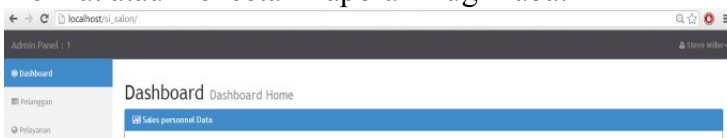

Gambar 16. Halaman kasir
Pada gambar 16, adalah halaman untuk kasir. Fasilitas yang ada pada halaman ini adalah untuk mengelola data Pelanggan, layanan dan tarif, pembayaran layanan oleh pelanggan.

Keunggulan dari aplikasi sistem informasi akuntansi IQ Salon ini antara lain:

a. Sistem bisa untuk multi user yaitu: administrator, customer service dan kasir

b. Sistem berbasis web, ke depan bisa di hosting wed apabila punya cabang salon, sehingga laporan keuangan dapat terpantau dengan baik.

\section{Kesimpulan}

Pada penelitian ini dapat diambil beberapa kesimpulan antara lain:

a. Sistem informasi akuntansi pada IQ Salon yang dibangun dengan menggunakan bahasa pemrograman PHP dan MySQL sebagai databasenya.

b. Laporan yang dihasilkan antara lain laporan Jurnal, Neraca, Buku Besar dan Rugi Laba. Laporan tersebut mempermudah pemilik IQ Salon untuk mengontrol dan mengambil keputusan. Selain itu juga mempermudah karyawan untuk melayani pelanggan dalam hal pembayaran dari layanan yang telah diberikan.

c. Kelebihan sistem ini bisa untuk multi user dan bisa berbasis web, apabila nantinya salon memiliki cabang.

\section{Daftar Pustaka}

Bodnar, George H., William S. Hopwood, 2000. Sistem Informasi Akuntansi, Edisi Keenam, Terjemahan Amir Abadi Jusuf, Rudi M. Tambunan, Salemba Empat, Buku Satu, Jakarta.

Gundodiyoto, S., 2007. Audit Sistem Informasi + Pendekatan Cobit, Jakarta: Mitra Wacana Media.

Hall, J.A, 2001. Sistem Informasi Akuntansi, Edisi Ketiga, Cetakan Pertama, Terjemahan : Amir Abadi Jusuf, Salemba Empat, Buku Satu, Jakarta.

Jogiyanto, H.M. 2007. Analisis dan Desain Sistem Informasi: Pendekatan Terstruktur Teori dan Praktik Aplikasi Bisnis, Yogyakarta: Andi Offset.

Mulyadi, 2001. Sistem Akuntansi, Edisi Ketiga, Cetakan Ketiga, Salemba Empat,Jakarta.

Romney, Marshall B. dan Paul John Steinbart, 2004. Sistem Informasi Akuntansi, Edisi Kesembilan, Cetakan Pertama, Terjemahan Dewi Fitria Sari, dan Beny Amos Kwary, S.S., Salemba Empat, Jakarta. 
Suwarno, A.E., 2004. Pengendalian intern dalam sistem informasi akuntansi berbasis komputer. Jurnal Akuntansi dan Keuangan, 3(1), 38-50.

Tjahjono, A. dan Sulastiningsih. 2003. Akuntansi Pengantar Pendekatan Terpadu Buku 1. Yogyakarta: UPP AMP YKPN.
Warren, Carl S., James M. Reeve, Phillip E. Fess, 2005. Pengantar Akuntansi, Edisi 21, Terjemahan Aria Farahmita, Amanugrahani, Taufik Hendrawan .Salemba Empat, Jakarta.

Widjajanto, Nugroho, 2001. Sistem Informasi Akuntansi, Erlangga, Jakarta. 